\title{
Novel Expression of the Tyrosine Hydroxylase Gene Requires Both Acidic Fibroblast Growth Factor and an Activator
}

\author{
Xinyu Du, Natalie D. Stull, and Lorraine lacovitti \\ Institute of Neuroscience, Department of Neurology, Hahnemann University, Philadelphia, Pennsylvania 19102-1192
}

Substances found in the soluble extract of muscle can alter the differentiative fate of certain brain neurons in culture by triggering novel expression of the gene for the catecholamine biosynthetic enzyme tyrosine hydroxylase (TH) (lacovitti et al., 1989; lacovitti, 1991). In this study, we demonstrate that $\mathrm{TH}$ induction in cultured noncatecholamine neurons from the mouse striatum requires the cooperative interaction of at least two substances found in muscle. Purification studies, combined with biological assay, revealed that one necessary component is acidic fibroblast growth factor (aFGF), and the other, an unidentified molecule(s) of $<\mathbf{1 0} \mathrm{kDa}$ molecular weight that activated aFGF. Thus, muscle-derived aFGF, if incubated in the presence but not the absence of the $<10 \mathrm{kDa}$ fraction of muscle, induced a dosedependent increase in the number of striatal neurons that novelly express TH. This expression was blocked by prior incubation and protein A precipitation of the factor with polyclonal antibodies to aFGF (1:200-1:1000). Similar to musclepurified aFGF, commercial preparations of native bovine and human recombinant aFGF $(0.1-100 \mathrm{ng} / \mathrm{ml})$ were potent inducers of $T H$ when coincubated with the $<10 \mathrm{kDa}$ activator. In contrast, basic FGF produced little and FGF-7 no induction of TH.

Unlike the unidentified activating agent in muscle, heparin (20-500 mU), a known activator of aFGF, did not potentiate the factor's TH-inducing activity. Nonetheless, heparatinase $(100 \mathrm{mU})$ prevented TH induction by aFGF and its activator, indicating that binding of heparan sulfated proteoglycans is necessary for the effect.

These findings suggest that both aFGF and an unknown activator may be important partners in signaling TH gene expression during the differentiation of a catecholamine phenotype in brain neurons.

[Key words: fibroblast growth factor, tyrosine hydroxylase, muscle, striatal neurons, tissue culture, dopamine phenotype]

Over the last several years, studies from this laboratory have suggested the existence of a prospective CNS differentiation factor(s) in muscle. This notion originated with the unexpected observation that muscle and its soluble components could dramatically alter the differentiative course of certain subsets of

Received Mar. 30, 1994; revised May 16, 1994; accepted June 13, 1994.

We are grateful to Dr. Jim Miller and Mr. Robert Rosenfeld for their technical support and scientific suggestions. This work was supported by NIH NS24204 and a research gift from Amgen, Inc.

Correspondence should be addressed to Dr. Lorraine Iacovitti at the above address.

Copyright (c) 1994 Society for Neuroscience $0270-6474 / 94 / 147688-07 \$ 05.00 / 0$ brain neurons at precise stages in their development. Thus, when neurons were isolated from embryonic day (E) 13 cerebral cortex or striatum and grown in coculture with heart, skeletal muscle, vasculature, clonal muscle cells (L6 line), or their soluble extracts, as many as $80 \%$ of neurons were immunoreactive for the catecholamine (CA) biosynthetic enzyme tyrosine hydroxylase (TH) (Iacovitti et al., 1989; Iacovitti, 1991) even though, in vivo, they did not manufacture CA neurotransmitters. The increase in TH immunoreactivity was accompanied by parallel increments in TH activity and mRNA levels encoding the enzyme. Since neither muscle nor its extract improved the viability or caused the proliferation of TH neurons in these cultures (Iacovitti et al., 1989), the increase in TH expression was not attributed to the influence of trophic or mitogenic factors. Rather, we concluded that muscle contained a putative differentiation factor(s) capable of redirecting the biochemical fate of these non$\mathrm{CA}$ neurons by triggering induction of the $\mathrm{TH}$ gene. This factor(s) was thus broadly termed muscle-derived differentiation factor(s) (MDF), pending its molecular identification. Although a number of physiological stimuli and/or extracellular molecules amplify existing TH gene expression (Black et al., 1985; Stachowiak et al., 1985; Tank et al., 1985; Faucon-Biguet et al., 1986; Harrington et al., 1987; Lewis and Chikaraishi, 1987; Gizang-Ginsberg and Ziff, 1990; Costa et al., 1991; Joh et al., 1993), this was the first example, in brain, of a differentiation factor(s) inducing novel transcription of a quiescent neurotransmitter gene. Because of its potential role in the development and regulation of TH gene expression in the brain, we embarked upon the purification and identification of the agent(s) in musclc responsible for this unique function. In this article, we will present data to support the conclusion that MDF activity requires participation of at least two substances present in muscle extract: acidic fibroblast growth factor (aFGF) and an unidentified molecule(s) that activates aFGF.

\section{Materials and Methods}

Purification procedures. Cloned L6 rat skeletal muscle cells (ATCC CRL 1458) were grown to near confluence by the MIT Cell Culture Center, harvested, and stored at $-80^{\circ} \mathrm{C}$. One kilogram of thawed cells was homogenized in 3 liters of iced $10 \mathrm{~mm}$ sodium phosphate buffer (PB) pH 7.2. The homogenate was separated into soluble and insoluble components by centrifugation $(2500 \mathrm{rpm}$ for $10 \mathrm{~min}$ in a Sorvall SS-34 rotor; supernatant was decanted and recentrifuged at $32,000 \mathrm{rpm}$ for $60 \mathrm{~min}$ in a Beckman type 70ti rotor). The supernatant fraction was then twice filtered through an Amicon ultrafiltration membrane with a molecular weight cutoff of $10 \mathrm{kDa}$. The low-molecular-weight components $\left(<10 \mathrm{kDa}\right.$ fraction) were stored at $-80^{\circ} \mathrm{C}$ for subsequent use in the bioassay. The $>10 \mathrm{kDa}$ fraction was purified by sequential fractionation, anion exchange, and heparin affinity chromatography.

Chromatographic procedures. The $>10 \mathrm{kDa}$ fraction was loaded onto a Whatman DEAE cellulose column $(2.5 \times 15 \mathrm{~cm})$ equilibrated with 

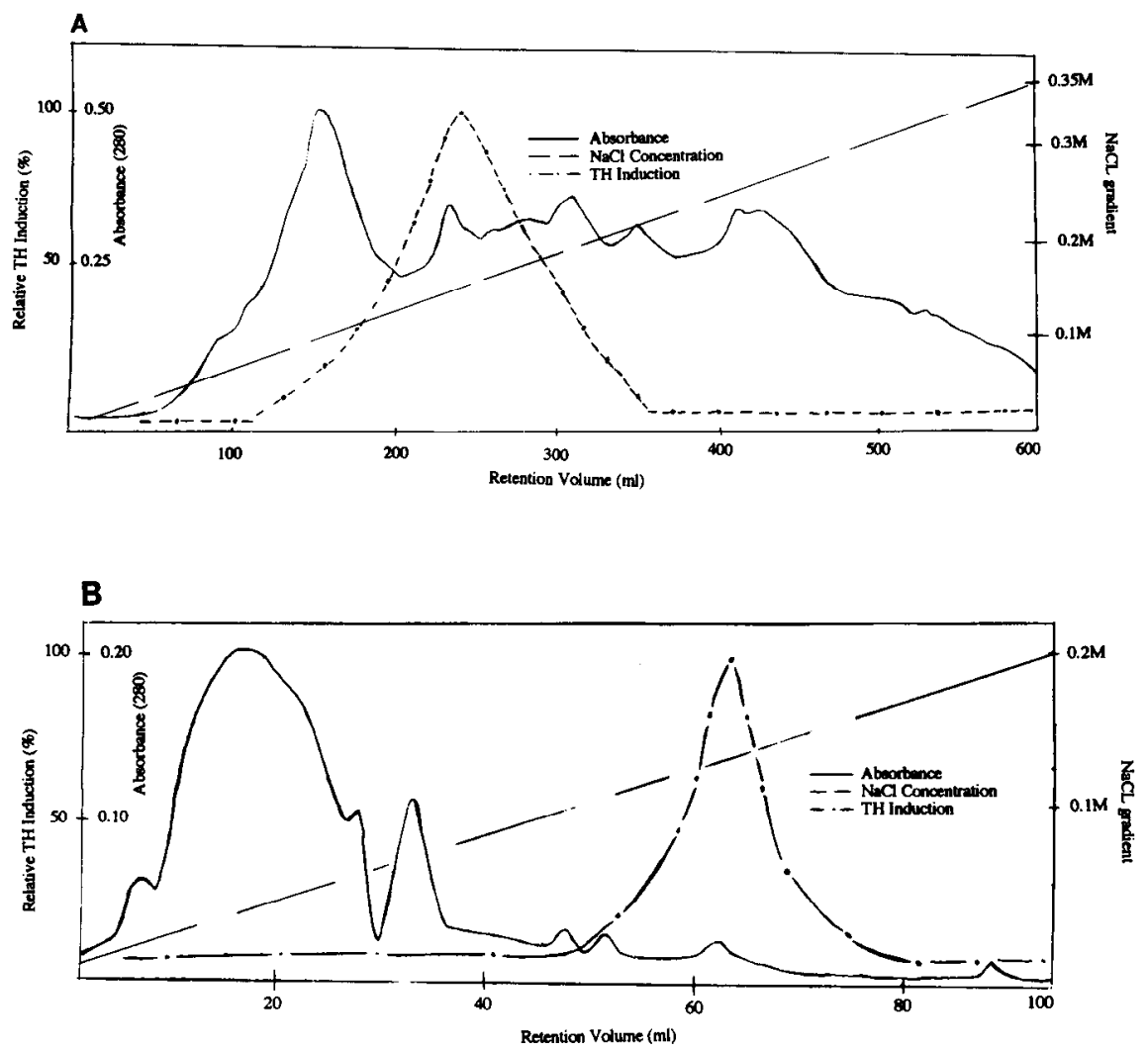

Figure 1. Chromatograms obtained during the purification of the $>10 \mathrm{kDa}$ fraction of L6. $A$, The $>10 \mathrm{kDa}$ fraction was loaded onto a Whatman DEAE cellulose column $(2.5 \times 15 \mathrm{~cm})$ equilibrated with $10 \mathrm{~mm}$ sodium phosphate buffer (PB) $\mathrm{pH} 7.2$ at gravity flow. The column was washed with 1 liter of PB and protein was eluted from the column with $500 \mathrm{ml}$ of a linear gradient of $0.1-$ $0.35 \mathrm{M} \mathrm{NaCl}-\mathrm{PB}$ at a flow rate of $12 \mathrm{ml} /$ hr using an LKB-Pharmacia 223 peristaltic pump. The activity of each fraction was monitored by bioassay in culture (22). Profile of protein (solid line) is compared to bioactivity (TH induction) (broken line). B, Heparin affinity chromatography: active fractions recovered from the DEAE column were pooled and loaded onto a heparin sepharose column washed with $0.5 \mathrm{M}$ NaCl-PB (pH 7.2). Bound material was eluted in a linear gradient of $0.5 \mathrm{M} \mathrm{NaCl}$ and $2.0 \mathrm{M} \mathrm{NaCl}-\mathrm{PB}$. Profile of protein (solid line) is compared to bioactivity (TH induction) (broken line).
10 mM sodium phosphate buffer (PB) at a normal flow rate. The column was washed with 1 liter of $P B$ and protein eluted from the column with $500 \mathrm{ml}$ of a linear gradient of $0.1-0.35 \mathrm{M} \mathrm{NaCl}-\mathrm{PB}$ at a flow rate of 12 $\mathrm{ml} / \mathrm{hr}$ using an LKB-Pharmacia 223 peristaltic pump. The activity of cach fraction was monitorcd by bioassay in culture. Next, active fractions recovered from the DEAE column were pooled and loaded onto a heparin sepharose column washed with $0.5 \mathrm{M} \mathrm{NaCl}$. Bound material was eluted in a linear gradient of $0.5 \mathrm{M} \mathrm{NaCl}$ and $2.0 \mathrm{M} \mathrm{NaCl}$. Samples were analyzed by sodium dodecyl sulfate-PAGE (SDS-PAGE) on a $15 \%$ polyacrylamide gel stained with silver (Bio-Rad) or subjected to Western blot analysis using polyclonal antibodies to aFGF and bFGF (1:500; Sigma).

Bioassays. A relatively rapid and reproducible bioassay was developed for test column fractions. A method for microseeding embryonic neurons was first established. Mouse neurons (which exhibited a more robust response than the rat neurons used previously) were isolated from the E13 striatum since they were the most MDF responsive nonCA cell population (Iacovitti, 1991). Neurons were dissected and trypsin $(0.01 \%)$ dissociated as described elsewhere (Iacovitti et al., 1989). After a $1 \mathrm{~d}$ stabilization period, cultures were incubated overnight in media containing the test column fractions diluted 1:1 with the $<10 \mathrm{kDa} \mathrm{L6}$ activator fraction. The following day, cultures were fixed in $4 \%$ paraformaldehyde, immunocytochemically stained for the localization of $\mathrm{TH}$, and scored for TH induction as described previously (Iacovitti et al., 1989). One unit of biological activity was defined as half the maximal number $(80 \%)$ of neurons that were TH immunoreactive.

\section{Results}

\section{Strategy for purification}

A kilogram of cloned L6 muscle cells (grown by the MIT Cell Culture Center) was homogenized and separated into soluble and insoluble components by high-speed centrifugation (Fig. 1). Activity was restricted entirely to the soluble fraction (Iacovitti et al., 1989), which was subsequently applied to a variety of test chromatographic resins. Recovery of bioactivity was assayed by overnight incubation of E13 mouse striatal neurons in culture media supplemented with individual column fractions as de- scribed previously (Iacovitti et al., 1989). Cultures were then fixed and immunocytochemically stained for the localization of TH and scored for TH induction after microscopic examination. Attempts to size the activity by membrane fractionation led to the important and unexpected discovery that the responsible element(s) did not behave as a single species. Thus, when the soluble extract was passed through an Amicon ultrafiltration membrane with a molecular weight cutoff of $10 \mathrm{kDa}$, bioactivity was not recovered from either the $<10 \mathrm{kDa}$ or the $>10 \mathrm{kDa}$ fraction alone but could be reconstituted by the addition of both fractions together. This suggested that $\mathrm{TH}$-inducing activity required cooperation of one or more substances present in each of these fractions and would therefore require two or more laborintensive purifications.

A strategy for uncoupling the activities was consequently adopted so that purification of the $>10 \mathrm{kDa}$ molecule(s) could proceed while delaying to a later time that of the low-molecularweight substance(s). This meant that all test fractions from $>10$ $\mathrm{kDa}$ purification would bioassay negative even though some contained the active agent unless the low-molecular-weight component(s) was added to each test fraction before bioassay. Therefore, a large stock of the $<10 \mathrm{kDa}$ fraction of $\mathrm{L} 6$ was prepared and stored at $-80^{\circ} \mathrm{C}$. The optimal concentration of $<10 \mathrm{kDa}$ fraction was determined beforehand to be a twofold dilution of the starting material. Therefore, the $<10 \mathrm{kDa}$ fraction was added in all bioassays (final dilution of $1: 1$ in sample column fraction) to monitor activity during purification of the $>10 \mathrm{kDa}$ factor(s).

\section{Purification of $>10$ kDa factor}

The factor was purified by sequential fractionation, anion exchange and heparin affinity chromatography (Fig. 1, Table 1). This scheme yielded a purification of 11,733 -fold with a recov- 


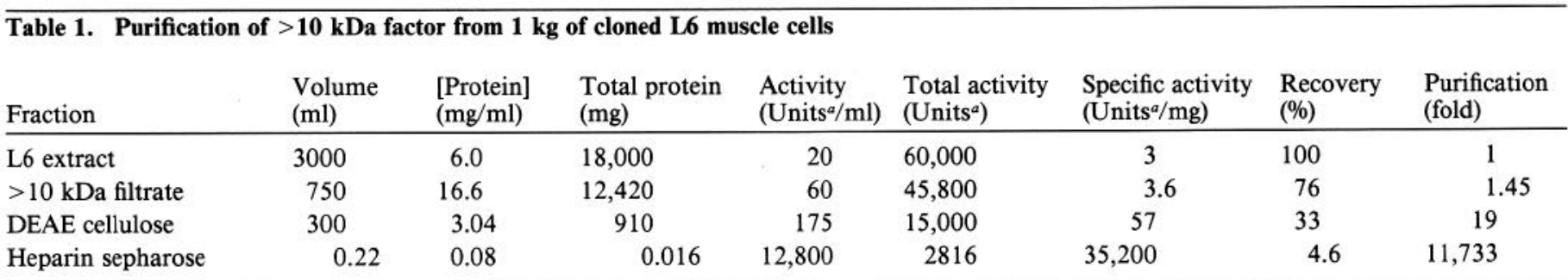

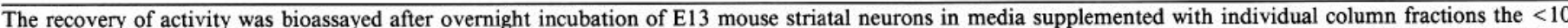
$\mathrm{kDa}$ activator. Cultures were then fixed and immunocytochemically stained for the localization of TH and scored for TH induction after microscopic examination.

${ }^{a}$ Units of activity are expressed as half the maximal number of neurons stained positively with $\mathrm{TH}$ antibodies.

ery of $4.6 \%$ of the original starting material and a specific activity of $35,200 \mathrm{U} / \mathrm{mg}$ protein in the bioassay (Table 1). Fractions obtained during the purification were analyzed by sodium dodecyl sulfate-polyacrylamide gel electrophoresis (SDS-PAGE; $15 \%$ ) stained with silver (Fig. 2). Purification resulted in the migration of one band of $16 \mathrm{kDa}$ molecular weight. There was not, however, sufficient protein recovered after transfer to nitrocellulose for $\mathrm{N}$-terminal amino acid sequencing.

However, because of the molecule's avid affinity for heparin and its $16 \mathrm{kDa}$ molecular weight, the distinct possibility was raised that a member of the fibroblast growth factor (FGF) family had been purified from L6 cells. Based on its negative charge, acidic FGF (aFGF) was the most likely candidate. Since muscle is indeed known as a rich source of aFGF (reviewed in Baird and Bohlen, 1990), we examined fractions from each purification step using Western blot analysis. As seen in Figure 3, the antibodies cross-reacted with commercially obtained recombinant human aFGF and with similar protein bands in the frac-

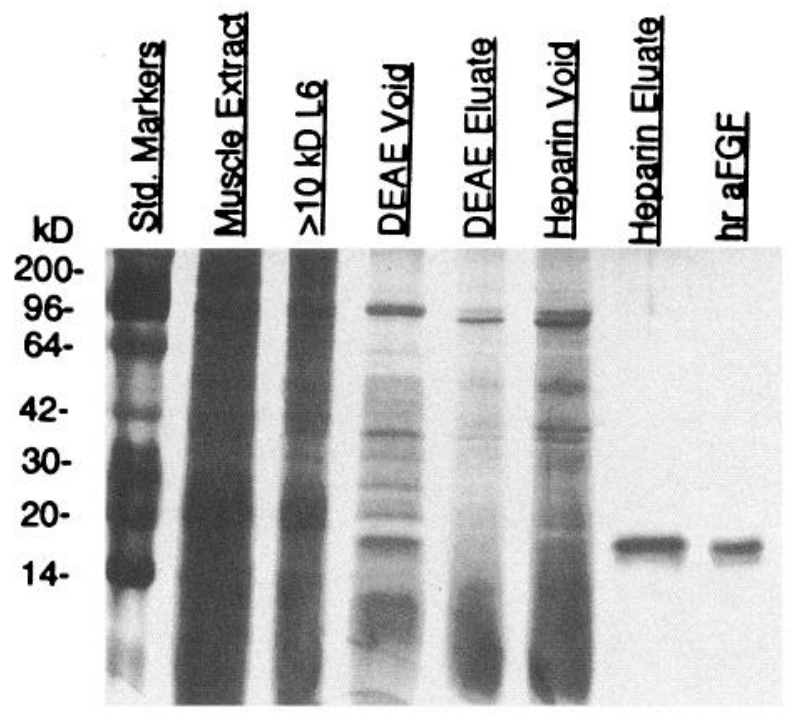

Figure 2. Analysis of fractions from the purification. Samples were analyzed by SDS-PAGE on a $15 \%$ polyacrylamide gel that was then stained with silver (Bio-Rad). Shown on the overexposed silver stained gel are the following samples (from the left): Rainbow protein molecular weight standards (Amersham), L6 muscle extract ( $0.25 \mu \mathrm{g}$ of protein), $>10 \mathrm{kDa}$ L6 fraction $(0.25 \mu \mathrm{g}$ of protein), DEAE-cellulose void fraction $(0.20 \mu \mathrm{g}$ of protein), DEAE-cellulose salt fraction $(0.20 \mu \mathrm{g}$ of protein), heparin sepharose void fraction $(0.20 \mu \mathrm{g}$ of protein), heparin sepharose salt fraction ( $0.05 \mu \mathrm{g}$ of protein), $\mathrm{hr}$ aFGF (Amgen) $(0.10 \mu \mathrm{g}$ of protein). tions isolated during purification. Antibodies to basic FGF (bFGF) were not cross-reactive (data not shown).

\section{Role of aFGF in TH induction}

Western blot analysis provided direct evidence that aFGF had indeed been purified from L6 cells. However, these experiments did not establish whether aFGF or some other protein inconspicuous by gel electrophoresis was responsible for the observed bioactivity. To test aFGF's role directly, a commercially available preparation of human recombinant aFGF (hr aFGF) was assayed over a wide range of concentrations in both the absence and presence of the $<10 \mathrm{kDa}$ L6 fraction and its dose-response curve compared with that of purified $>10 \mathrm{kDa}$ factor. As shown in Figure 4, both $\mathrm{hr}$ aFGF and the purified $>10 \mathrm{kDa}$ factor performed identically in the bioassay. In both cases, TH induction reached saturation at $10 \mathrm{ng} / \mathrm{ml}$ of factor when cotreated with the $<10 \mathrm{kDa}$ fraction.

However, these experiments did not eliminate the unlikely possibility that TH might be induced by both aFGF and some other muscle-derived protein that copurified with aFGF. To address this issue further, we tested whether polyclonal antibodies to aFGF (anti-aFGF) could inhibit the TH-inducing capacity of the $>10 \mathrm{kDa}$ factor. Because the only commercially

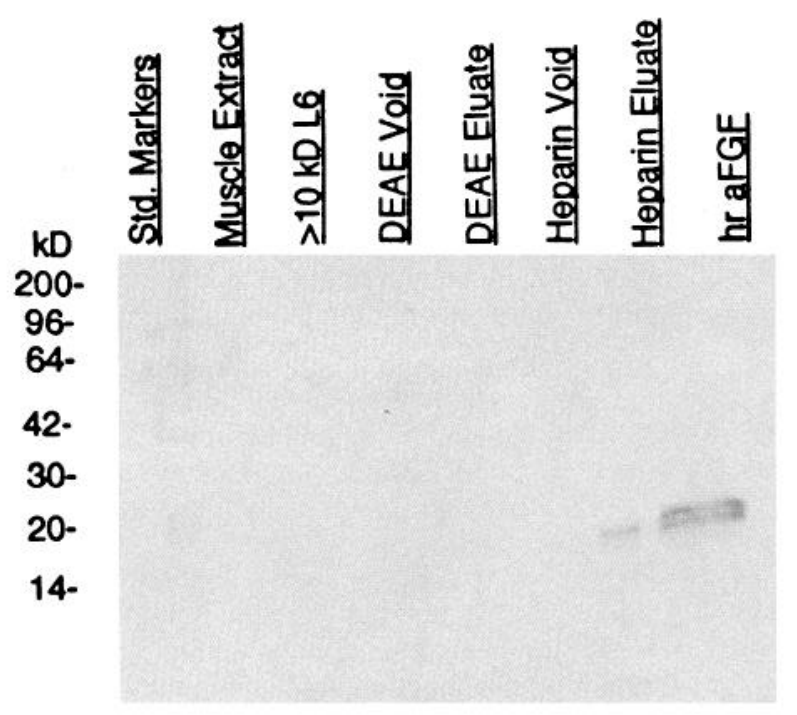

Figure 3. Western blot of the identical fractions analyzed in Figure 2 by SDS-PAGE on $15 \%$ polyacrylamide gel reacted with polyclonal antibodies to bovine aFGF (1:500; Sigma F-5521; no cross-reactivity with bFGF observed on immunoassay). 


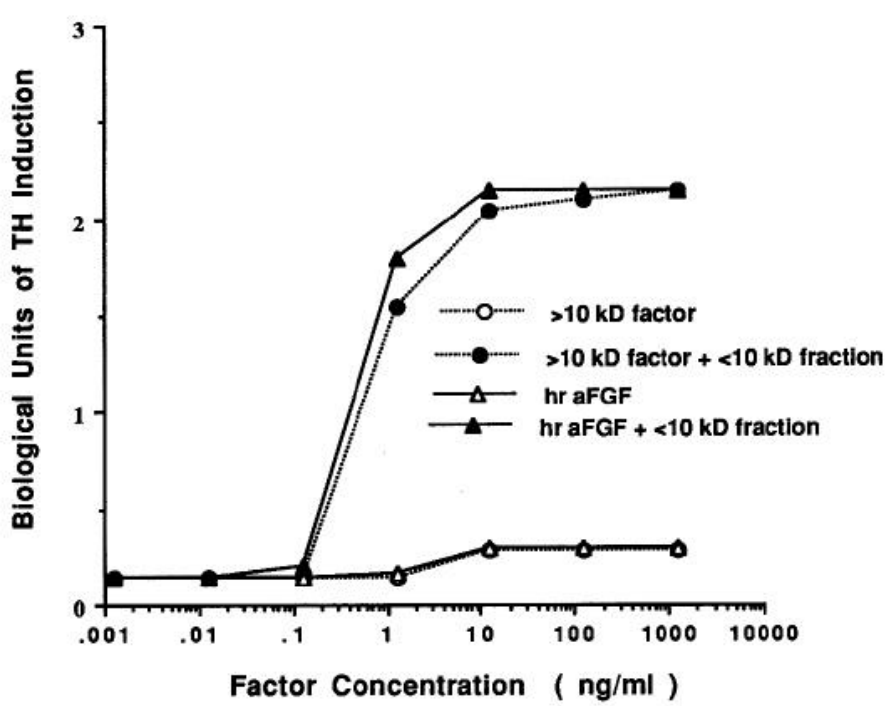

Figure 4. Dose dependency of the effect of $>10 \mathrm{kDa}$ factor and $\mathrm{hr}$ aFGF on the number of TH-immunoreactive striatal neurons. Cultures were grown both in the absence and presence of the $<10 \mathrm{kDa}$ fraction of L6. Note that dose-response curves are identical for both factors, requiring in all cases the presence of an additional substance found in the $<10 \mathrm{kDa}$ fraction.

available antibodies were raised against a native bovine aFGF preparation (which might also inadvertently contain a protein that copurifies with aFGF), we generated activity inhibition curves against $\mathrm{hr}$ aFGF as well. Thus, various dilutions of antiaFGF were incubated at $37^{\circ} \mathrm{C}$ with $>10 \mathrm{kDa}$ factor (recovered after DEAE chromatography) or $10 \mathrm{ng} / \mathrm{ml}$ of $\mathrm{hr}$ aFGF. After protein A precipitation, the supernatant was added to striatal cultures and TH bioassayed. Although activity was never totally eliminated, anti-aFGF produced a dose-dependent decrease in the TH inducing activity of both the $>10 \mathrm{kDa}$ factor and $\mathrm{hr}$ aFGF (Fig. 5), neutalizing $50 \%$ of bioactivity at an identical dilution $(1: 2000)$. These results strongly suggest that the most likely source of TH inducing activity in L6 muscle is indeed aFGF.

\section{Comparison of aFGF and other FGF family members}

We next compared a number of commercial preparations of aFGF as well as other members of the FGF gene family for their TH-inducing capacity. As had been observed in our original experiments (Iacovitti et al., 1989), incubation of neurons with native bovine aFGF alone did not induce TH expression in nonCA neurons. However, as the number of trials in the study grew $(n=37)$, we found that $16 \%$ of the platings (6 of 37 trials) treated with either bovine aFGF or hr aFGF exhibited low but detectable levels of TH induction (Fig. 6). On these occasions, the number of neurons induced to express TH was variable, reaching, at most, half-maximal levels. However, in all 37 experimental trials, regardless of the basal levels of activity observed with aFGF alone, the addition of the $<10 \mathrm{kDa} \mathrm{L} 6$ fraction increased TH expression to maximal levels. These results suggest then that full induction of the TH gene in competent neurons requires the presence of both aFGF and an added activator substance $(<10 \mathrm{kDa} \mathrm{L6})$. It is not yet clear why, on some occasions, incubation solely with aFGF elicited low levels of expression in some neurons. Since the variable response to aFGF

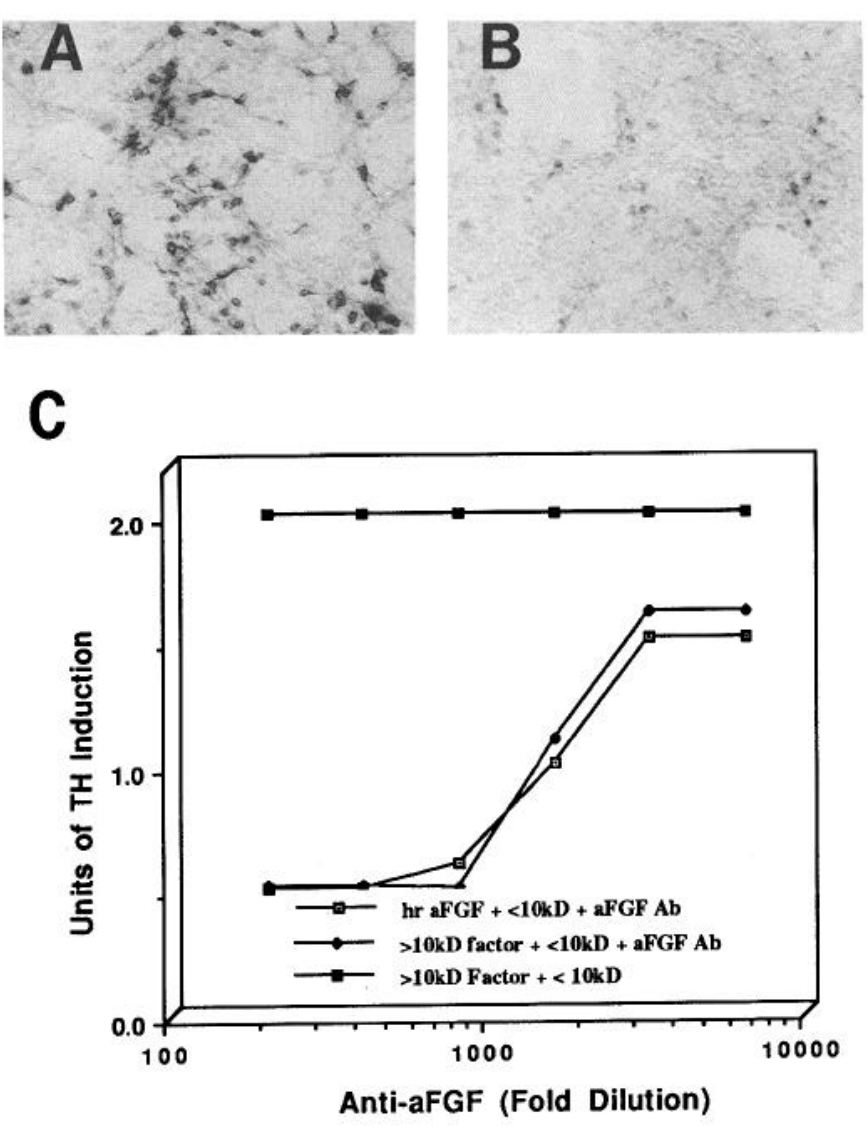

Figure 5. Immunocytochemical localization of $\mathrm{TH}$ in cultured striatal neurons. $A$, Neurons were incubated in media containing an active partially purified $>10 \mathrm{kDa}$ fraction (recovered after DEAE chromatography) in the presence of the $<10 \mathrm{kDa}$ activator. After overnight incubation, cultures were fixed in $4 \%$ paraformaldehyde and $\mathrm{TH}$ was immunocytochemically localized as described previously. Note the number of neurons expressing high levels of TH. $B$, The same fraction (as in $A$ ) was first incubated with aFGF antibodies (diluted 1:400). Immune complexes were then removed by protein A precipitation. Striatal cultures were next incubated in media containing the supernatant and the $<10 \mathrm{kDa}$ activator. $C$, Activity inhibition curves for the $>10 \mathrm{kDa}$ factor or $\mathrm{hr}$ aFGF after preincubation with various dilutions of aFGF antibodies.

occurred both in serum-containing and in serum-free media, it is unlikely that activation by a serum component accounted for basal TH expression. An alternate possibity is that the neurons themselves differ from plating to plating. Conceivably, at some but not all developmental stages, activators might be present intrinsically in embryonic neurons, thus allowing partial TH induction when aFGF is exogenously supplied. Consistent with this notion is the fact that, within any one plating, aFGF-induced responses were identical from one culture to another.

Importantly, other FGF family members did not behave in a similar fashion to aFGF in the bioassay (Fig. 6). Low levels of TH inducing activity were only rarely observed when neurons were incubated in media containing an analog of aFGF (designed by Amgen for its increased efficacy in the fibroblast proliferation assay) or bFGF. The latter finding was especially surprising since, in all other biological systems studied to date, bFGF is 10-100 times more potent than aFGF in eliciting a biological response. As seen previously with aFGF, coincubation of these less active FGF molecular forms with the $<10 \mathrm{kDa}$ L6 fraction 


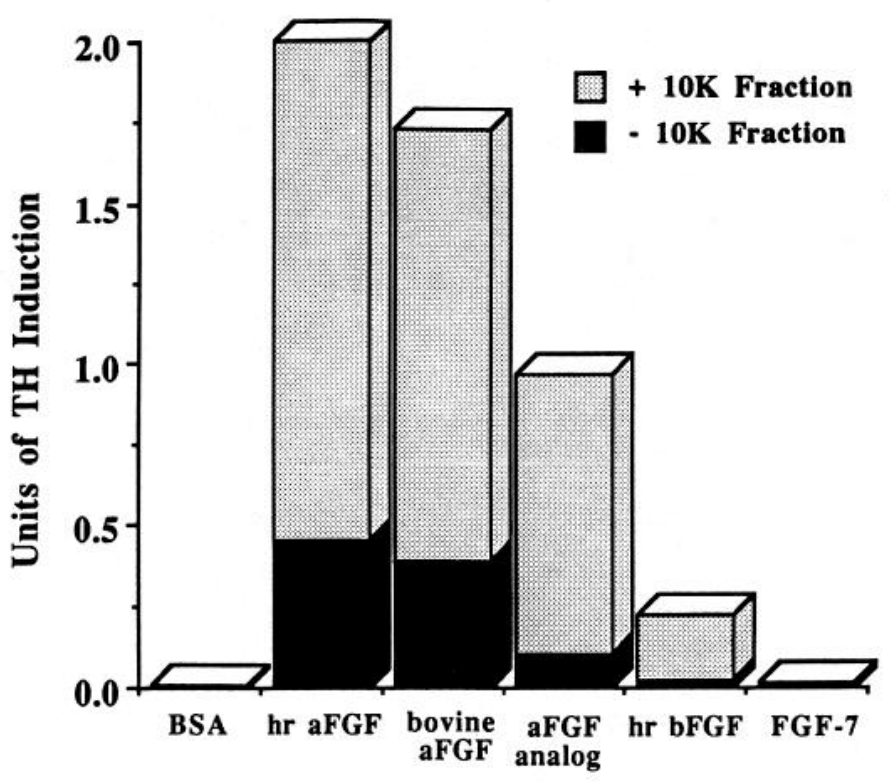

Figure 6. Induction of TH in E13 striatal neurons, dissected as described previously, and incubated overnight in either serum-free or FCScontaining media supplemented with $10 \mathrm{ng} / \mathrm{ml}$ of bovine serum albumin ( $B S A$; control) or various preparations of FGF family members, including human recombinant aFGF ( $h r a F G F$; Amgen), native bovine aFGF (from R \& D Systems), analog of aFGF (Amgen), human recombinant bFGF ( $h r b F G F$; Amgen), and FGF-7 (Amgen) in the absence (solid bar) or presence (shaded bar) of the $<10 \mathrm{kDa}$ fraction of L6. Bars represent the average number of biological units observed in 25 experimental platings [ 1 unit of activity equals half the maximal number $(80 \%)$ of neurons stained positively with TH antibodies]. Note that low levels of TH induction were sometimes observed after incubation with aFGF or bFGF but not FGF-7 (a.k.a. KGF). These basal levels were greatly increased by simultaneous incubation with the $<10 \mathrm{kDa}$ activator fraction.

resulted in a modest increase in $\mathrm{TH}$ induction (Fig. 6). In contrast, FGF-7 (a.k.a. keratinocyte growth factor or KGF) was unable to produce any detectable TH gene induction when administered alone or in combination with the low-molecularweight L6 fraction.

\section{Role of the activator in aFGF's induction of $T H$}

These findings clearly demonstrate that although members of the FGF gene family are important participants in TH expression, the addition of an activator substance found in the $<10$ $\mathrm{kDa}$ fraction (which itself has no TH-inducing activity) is required for maximal expression of the $\mathrm{TH}$ gene. Its addition increases in a dose-dependent manner the number of neurons induced to express $\mathrm{TH}$ by hr aFGF (Fig. 7). Because heparin and heparan sulfated proteoglycans (HSPG) are well known activators/stabilizers of aFGF in other biological models (increasing aFGF activity 10-100-fold to the level of bFGF) (Mathew et al., 1985; Yayon et al., 1991), we examined their role in this system. Since no commercial HSPGs are currently available, our studies were limited to testing the role of soluble heparin. In six separate experiments, the simultaneous incubation of varying concentrations of heparin (Sigma H-3149; 20-500 $\mathrm{mU})$ with aFGF or its analog $(1 \mathrm{pg} / \mathrm{ml}$ to $100 \mathrm{ng} / \mathrm{ml})$ in serumfree media did not increase the levels of $\mathrm{TH}$ induction in striatal cultures (data not shown). Higher concentrations of heparin $(>500 \mathrm{mU})$ commonly used in fibroblast model systems were not evaluated in our assay system since they resulted in de-

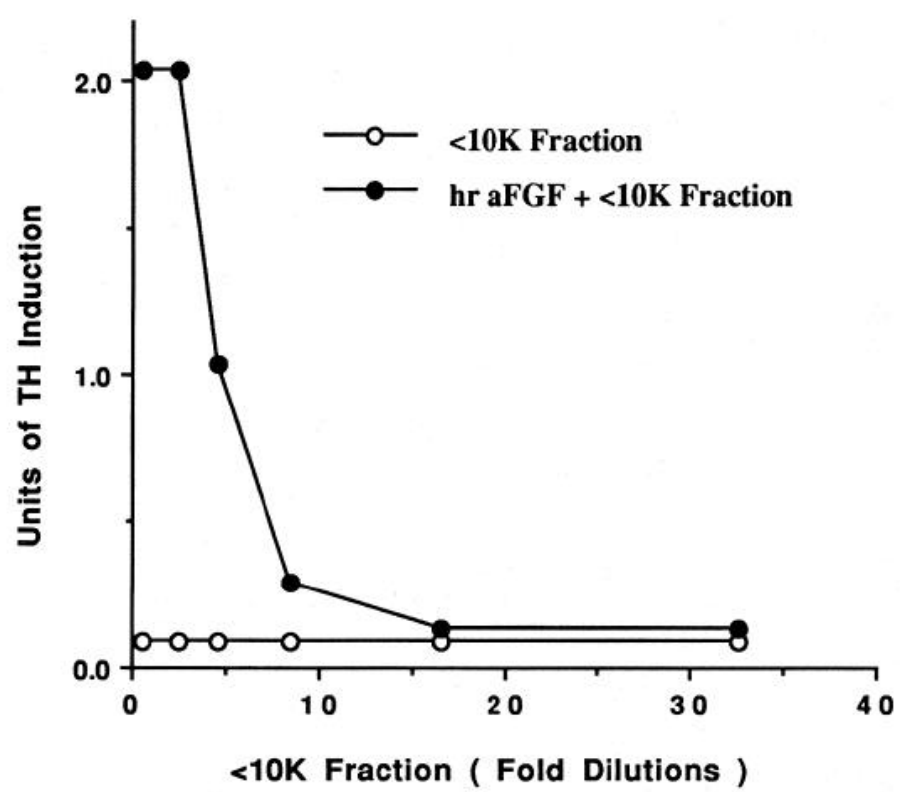

Figure 7. Dose dependency of the effect of the $<10 \mathrm{kDa}$ activator fraction on hr aFGF-induced $\mathrm{TH}$ expression. Cultures of E13 striatal neurons, stabilized $1 \mathrm{~d}$ in vitro, were treated with various concentrations of the $<10 \mathrm{kDa}$ activator fraction in the absence (open circles) or presence (solid circles) of $\mathrm{hr}$ aFGF. One day later, cultures were immunocytochemically stained and assessed for $\mathrm{TH}$ induction.

tachment of most neurons from the culture dish. Nonetheless, our findings indicate that soluble heparin does not enhance the inductive signal (aFGF) and is therefore unlikely to be the activating element present in the $<10 \mathrm{kDa}$ L6 fraction.

Interestingly, however, pretreatment of striatal cultures with high concentrations $(100 \mathrm{mU})$ of heparatinase (Sigma H-8891 EC 4.2.2.8.), which destroys cell surface HSPG activity by removing the glycosaminoglycan side chains from the heparan sulfate core, prevented the induction of TH by aFGF and the $<10 \mathrm{kDa}$ fraction. Even though lower concentrations (1 mU), which were effective in other biological systems, failed to inhibit TH expression in our assay, these results suggest that binding to cell surface HSPG is indeed necessary for TH induction.

\section{Other growth factors do not activate aFGF}

In addition to heparin and HPSG, other known growth factors commonly implicated in the nervous system, were also investigated for their ability to activate aFGF. In particular, TGF $\beta$ has been found in some biological systems to potentiate bFGF actions (Globus et al., 1988; Parker et al., 1991). Cultures were therefore grown with aFGF and a cocktail of other factors, including NGF, CNTF, LIF, TGF $\beta$, IL-1, IGF-I, and EGF (many of which are larger than the suspected $<10 \mathrm{kDa}$ size of the activator molecule). The activity of aFGF was not potentiated by the presence of these combined factors (data not shown).

\section{Discussion}

The term MDF was first coined to signify an agent in muscle possessing the unique ability to induce expression of the TH gene in non-CA brain neurons. It now seems certain that MDF activity is mediated by several substances present in the crude extract of L6 muscle cells and that their combined cooperation is required for full induction of the TH gene. Although the identity of all requisite elements is not yet known, several lines 
of evidence presented here demonstrate that one participant is aFGF. Thus, the purified $>10 \mathrm{kDa}$ L6 factor (believed to be aFGF), native bovine aFGF, and human recombinant aFGF, if combined with another necessary muscle-derived activating substance(s), all produce an identical dose-dependent induction in TH gene expression in cultured neurons of the mouse (and/ or rat) striatum. Further confirmation of aFGF's involvement is provided by the fact that prior precipitation with specific antibodies to aFGF substantially reduces TH gene-inducing capacity of both the $>10 \mathrm{kDa}$ muscle factor and hr aFGF.

Acidic FGF is a member of a family of at least seven distinct polypeptide growth factors, all of which are structurally related and probably derive from a common ancestral gene (Baird and Bohlen, 1990; Gospodarowicz, 1990). Along with its closely related isoform, basic fibroblast growth factor (bFGF), aFGF was first described for its ability to stimulate fibroblast proliferation (Gospodarowicz, 1974), hence its name. However, in the last decade, more than 30 other biological actions have been attributed to members of the FGF family (Esch et al., 1985; Gimenz-Gallego, 1985; Abraham et al., 1986; Jave et al., 1986). FGF's pleiotropic effects are thought to regulate many of the events in the developing embryo, including mitogenesis, trophism, and differentiation of the nervous system (Walicke et al., 1986; Unsicker et al., 1987; Ferrari et al., 1989; Hughes et al., 1993; Kilpatrick and Bartlett, 1993). Indeed, bFGF, which has been particularly scrutinized in this regard, has been shown to act as a mitogenic factor for neuroblasts (Baird and Walicke, 1989; Murphy et al., 1990). In postmitotic neurons, bFGF also serves as a trophic factor, enhancing the survival of cultured neurons from the cortex, hippocampus, spinal cord, and midbrain (Walicke et al., 1986; Unsicker et al., 1987; Baird and Walicke, 1989; Ferrari et al., 1989; Murphy et al., 1990; Hughes et al., 1993). In addition, FGF is believed to be a key factor in the morphological differentiation of the nervous system, promoting neurite formation and a mature anatomical configuration (Morrison et al., 1986; Walicke et al., 1986; Unsicker et al., 1987; Hatten et al., 1988; Ferrari et al., 1989). The results of the present study provide the first direct evidence that aFGF may also be an important signal in the biochemical differentiation of neurons by demonstrating induction of a specific and novel neurotransmitter gene, TH. Whether these in vitro results are indicative of an in vivo role for aFGF in the differentiation of a CA neurotransmitter phenotype is not yet known. If so, however, it would imply that all neurons that successfully express $\mathrm{TH}$ in the brain must possess receptors and an exogenous source of aFGF and its activator or must manufacture endogenous supplies of these substances. Consistent with this hypothesis is the fact that mesencephalic CA neurons (presumably dopamine neurons of the ventral midbrain) synthesize endogenous growth factor as well as respond to exogenous FGF at the appropriate stages of embryogenesis (Baird and Walicke, 1989; Murphy et al., 1990; Eckenstein et al., 1991; Kilpatrick and Bartlett, 1993; Nurcombe et al., 1993).

Although FGF ultimately results in nuclear (i.e., genetic) changes, it is presumed that, like other growth factors, its actions begin at the cell membrane by binding to a specific cell surface receptor (Klagsburg and Baird, 1991), which then triggers signal transduction systems and a cascade of events leading to $\mathrm{TH}$ induction. In other systems, FGF accomplishes this by first binding to its low-affinity receptor (HSPG) on the cell surface and, subsequently, to a high-affinity transmembrane tyrosine kinase receptor (Dionne et al., 1990; Yayon et al., 1991). The fact that, in the present study, heparatinase (which destroys HSPG) prevents TH induction underscores the requirement for low-affinity receptor binding for mediation of this FGF effect. In this regard, it is interesting to note that, as neuroblasts move from mitosis to the fully differentiated state, the low-affinity HSPG receptors present in the developing nervous system become differentially glycosylated, causing a shift in preferential binding from bFGF to aFGF (Nurcombe et al, 1993). This period, which begins at E11 (Nurcombe et al., 1993), corresponds precisely to the onset of the critical period for $\mathrm{TH}$ in duction described previously (Iacovitti et al., 1989; Iacovitti, 1991). Whether these low-affinity receptor changes are important for aFGF-mediated TH induction is not yet certain. Also unclear, is which classes of FGF transmembrane receptors must be subsequently activated for $\mathrm{TH}$ induction. However, because of its greater affinity for aFGF than bFGF, FGF receptor-4 (Partenen et al., 1991; Vanikka et al., 1992) seems the most likely candidate. Or, alternatively, a new and as yet undiscovered FGF receptor may underlie these biological effects. Resolution of these issues along with identification of transport pathways, second messenger systems, and the gene-activating sites required for $\mathrm{TH}$ induction by aFGF will necessitate our continued study.

Although aFGF plays a critical role in $\mathrm{TH}$ induction, our experiments clearly indicate that the presence of another substance(s) found in $\mathrm{L} 6$ muscle $(<10 \mathrm{kDa})$ is also required for expression of the TH gene. This unknown substance(s) appears to have no $\mathrm{TH}$-inducing capacity of its own but, in some as yet unexplained way, transforms aFGF-incompetent neurons into factor-responsive cells. The most likely candidate, heparin, does not appear to be the activating agent since it does not potentiate aFGF's actions. Although we could not directly test HSPG in our system, its large molecular size suggests that it, too, is unimportant in this regard. Nor did incubation of aFGF with other known growth factors provide the synergistic interaction needed for $\mathrm{TH}$ induction. Consequently, the $<10 \mathrm{kDa}$ muscle activator remains a critical but unknown entity.

Although the molecular mechanism underlying aFGF activation has not been addressed here, it is crucial to our understanding of TH gene induction. Presumably, it might be accomplished either by a direct molecular interaction between aFGF and its activator or by convergence of their molecular intermediaries during the signal transducing process. Interestingly, Yoon and Chickaraishi (1992) have demonstrated that tissuespecific expression of $\mathrm{TH}$ also requires an obligate interaction between two consensus sites on the TH gene. Presently, it is unclear whether the required cooperativity of multiple substances is a peculiarity of this particular system or, more intriguingly, represents a general principle governing the biochemical differentiation of the brain. In theory, the necessity for an additional activating substance(s) could provide an important mechanism for limiting the effects of such ubiquitous factors as FGF in the brain.

Apart from its role in initiating TH gene expression, our previous studies indicate that partially purified aFGF and its activator may also be important in the regulation of that expression. Thus, cultured embryonic dopamine neurons incubated with partially purified aFGF and activator express significantly more TH mRNA and enzyme (Iacovitti et al., 1992). Moreover, studies in vivo demonstrate that rats infused with these partially purified substances synthesize more dopamine and show greater recovery of motor function following chemical lesion of the 
nigrostriatal system (Iacovitti, 1994a,b). These studies, combined with the results of the present study, suggest that aFGF and its activator may be of utmost importance in both the differentiation of developing CA neurons and in their repair after injury in the adult brain.

\section{References}

Abraham JA, Mergia A, Whang JL (1986) Nucleotide sequence of a bovine clone encloding the angiogenic protein, basic fibroblast growth factor. Science 233:545-548.

Baird A, Bohlen P (1990) Fibroblast growth factors. In: The handbook of experimental pharmacology (Sporn MB, Roberts AB, eds), pp 369418. Berlin: Springer.

Baird A, Walicke PA (1989) Fibroblast growth factors. Brit Med Bull 54:438-452.

Black IB, Chikaraishi DM, Lewis EJ (1985) Trans-synaptic increase in RNA coding for tyrosine hydroxylase in a rat sympathetic ganglion. Brain Res 339:151-153.

Costa E, Olasmaa M, Guidotti A (1991) Vasoactive intestinal polypeptide facilitates tyrosine hydroxylase induction by cholinergic agonists in bovine adrenal chromaffin cells. Mol Brain Res 41:456-464.

Dionne CA, Crumley G, Bellot F, Kaplow JM, Serfoss G, Ruta M, Burgess WH, Jaye M, Schlessinger J (1990) Cloning and expression of two distinct high-affinity receptors cross-rcacting with acidic and basic fibroblast growth factors. EMBO J 9:2685-2692.

Eckenstein FP, Shipley GD, Nishi R (1991) Acidic and basic fibroblast growth factors in the nervous system: distribution and differential alteration of levels after injury of central versus peripheral nerve. $J$ Neurosci 11:412-419.

Esch F, Baird A, Ling N (1985) Primary structure of bovine pituitary basic fibroblast growth factor (FGF) and comparison with the aminoterminal sequence of bovine acidic FGF. Proc Natl Acad Sci USA 82:6507-6511.

Faucon-Biguet N, Buda M, Lamouroux A, Samolyk D, Mallet J (1986) Time course of the changes of TH mRNA in rat midbrain and adrenal medulla after a single cell injection of reserpine. EMBO J 5:287-291.

Ferrari G, Minozzi MC, Toffano G, Leon A, Skaper SD (1989) Basic fibroblast growth factor promotcs the survival and devclopment of mesencephalic neurons in culture. Dev Biol 133:140-147.

Gimenez-Gallego G, Rodkey K, Bennet C, Rios-Candelor M, DiSalve J, Thomas KA (1985) Brain derived acidic fibroblast growth factor: complete amino acid sequence and homologies. Science 230:13851388.

Gizang-Ginsberg E, Ziff EB (1990) Nerve growth factor regulates tyrosine hydroxylase gene transcription through a nucleoprotein complex that contains c-Fos. Genes Dev 4:447-491.

Globus RK, Patterson-Buckendahl P, Gospodarowicz D (1988) Regulation of bovine cell proliferation by fibroblast growth factor and transforming growth factor B. Endocrinology 123:98-105.

Gospodarowicz D (1974) Localization of a fibroblast growth factor and its effect alone and with hydrocortisone on $3 \mathrm{~T} 3$ cell growth. Nature 249:123-127.

Gospodarowicz D (1990) Fibroblast growth factor and its involvement in developmental processes. Curr Top Dev Biol 24:57-93.

Harrington CA, Lewis EJ, Krzemien D, Chikaraishi DM (1987) Identification and cell type specificity of the tyrosine hydroxylase gene promotor. Nucleic Acids Res 15:2362-2384.

Hatten ME, Lynch M, Rydel RE, Sanchez J, Joseph-Silverstein J, Moscatelli D, Rifkin DB (1988) In vitro neurite extension by granule neurons is dependent upon astroglial-derived fibroblast growth factor. Dev Biol 125:280-289.

Hughes RA, Sendtner M, Goldfarb M, Lindholm D, Thoenen H (1993) Evidence that fibroblast growth factor is a major-muscle-derived survival factor for cultured spinal motoneurons. Neuron 10:369-377.

Iacovitti L (1991) Effects of a novel differentiation factor on the development of catccholamine traits in non-catcholamine neurons from various regions of the rat brain: studies in tissue culture. J Neurosci $11: 2403-2409$.
Iacovitti L (1994a) Muscle derived differentiation factor and its regulation of the tyrosine hydroxylase gene in the developing, adult and lesioned rat brain. In: Trophic regulation of the basal ganglia: focus on dopamine neurons (Fuxe K, Agnati LF, Bjelke, Ottoson D, eds) pp 59-64. Oxford Hill: Pergamon.

Iacovitti $L$ (1994b) Centrally active differentiation factors in the nervous system. Pharmacology and Therapeutics, in press. New York: Pergamon.

Iacovitti L, Evinger MJ, Joh TH, Reis DJ (1989) A muscle derived factor induces expression of a catecholamine phenotype in cultured rat cerebral cortex. J Neurosci 9:3529-3537.

Iacovitti L, Evinger MJ, Stull ND (1992) Muscle-derived differentiation factor increases expression of the tyrosine hydroxylase gene and enzyme activity in cultured dopamine neurons from the rat midbrain Mol Brain Res 16:215.

Jave M, Howk R, Burgess W (1986) Human endothelial cell growth factor: cloning, nucleotide sequence, and chromosome localization. Science 233:541-545.

Joh TH, Kim K, Park D (1993) Parallel up-regulation of catecholamine biosynthetic enzymes by dexamethasone in PC1 2 cells. J Neurochem 60:946-951.

Kilpatrick TJ, Barlett PF (1993) Cloning and growth of multi potential neural precursors: requirements for proliferation and differentiation. Neuron 10:255-265.

Klagsburg M, Baird A (1991) A dual receptor system is required for basic fibroblast growth factor activity. Cell 6:229-231.

Lewis EJ, Chikaraishi DM (1987) Regulated expression of the tyrosine hydroxylase gene by epidermal growth factor. Mol Cell Biol 7:33323336.

Matthew WD, Greenspan RJ, Lander AD, Reichardt LF (1985) Immunopurification and characterization of a neuronal heparan sulfate proteoglycan. J Neurosci 5:1842-1850.

Morrison RS, Sharme A, DeVellis J, Bradshaw RA (1986) Basic fibroblast growth factor supports the survival of cerebral cortical neurons in primary culture. Proc Natl Acad Sci USA 83:7537-7541.

Murphy M, Drago J, Bartlett PF (1990) Fibroblast growth factor stimulates the proliferation and differentiation of neural precursor cells in vitro. J Neurosci Res 25:463-475.

Nurcombe V, Ford MD, Wildschut JA, Bartlett PF (1993) Development regulation of neural response to FGF-1 and FGF-2 by heparan sulfate protoglycan. Science 260:103-106.

Parker TG, Chow KL, Schwartz RJ, Schneider MD (1991) TGF- $\beta$-1 and fibroblast growth factor in cultured fibroblasts: interaction with the G-protein-mediated signaling pathways. Ciba Found Symp 157: 152-164.

Partanen J, Makela TP, Eerola E, Korhonen J, Hirvonen H, ClaessonWelsh L, Alitalo K (1991) FGFR-4, a novel acidic fibroblast growth factor receptor with a distinct expression pattern. EMBO J 10:13471354.

Stachowiak M, Sebbane R, Stricker EM, Zigmond J (1985) Effect of chronic cold exposure on tyrosine hydroxylase mRNA in rat adrenal glands. Brain Res 359:356-359.

Tank AW, Lewis EJ, Chikaraishi DM, Weiner N (1985) Elevation of RNA coding for tyrosine hydroxylase in rat adrenal gland by reserpine treatment and exposure to cold. J Neurochem 45:1030-1033.

Unsicker K, Heymanns J (1987) Neuroblastoma cells contain a trophic factor sharing biological and molecular properties with ciliary neurotrophic factor. Proc Natl Acad Sci USA 84:5459-5463.

Vainikka S. Partanen J, Bellosa P, Coulier F, Basilo C, Jaye M, Alitalo C (1992) EMBO J 11:4273-4280.

Walicke PA, Cowan WM, Ueno N, Baird A, Guillemin R (1986) Fibroblast growth factor promotes survival of dissociated hippocampal neurons and enhances neurite extension. Proc Natl Acad Sci USA 83:3012-3016.

Yayon A, Klagsbrun M, Esko JD, Leder P, Ornitz. DM (1991) Cell surface heparin like molecules are required for binding of basic fibroblast growth factor to its high affinity receptor. Cell 64:841-848.

Yoon S, Chikaraishi D (1992) Tissue-specific transcription of the rat tyrosine hydroxylase gene requires synergy between an AP-1 motif and an overlapping E-box containing dyad. Neuron 9:55-67. 